\title{
The Burden of Snakebite in Rural Communities in Kenya: A Household Survey
}

\author{
Gaby I. Ooms, ${ }^{1,2 \star}$ Janneke van Oirschot, ${ }^{1}$ Benjamin Waldmann, ${ }^{1}$ Dorothy Okemo, ${ }^{3}$ Aukje K. Mantel-Teeuwisse,${ }^{2}$ \\ Hendrika A. van den $\mathrm{Ham}^{2}$ and Tim Reed $^{1}$ \\ ${ }^{1}$ Health Action International, Amsterdam, The Netherlands; ${ }^{2}$ Utrecht Centre for Pharmaceutical Policy and Regulation, Division of \\ Pharmacoepidemiology and Clinical Pharmacology, Utrecht Institute for Pharmaceutical Sciences (UIPS), Utrecht University, Utrecht, The \\ Netherlands; ${ }^{3}$ Access to Medicines Platform Kenya, Nairobi, Kenya
}

\begin{abstract}
Annually, about 2.7 million snakebite envenomings occur worldwide, primarily affecting those living in rural regions. Effective treatment exists but is scarce, and traditional treatments are commonly used. To inform contextspecific policies in Kenya, this study aimed to determine the health-seeking behavior and the health, social, and economic burden of snakebites in rural communities. Nonprobability sampling was used to survey 382 respondents from four snakebite-endemic counties, from February to August 2020, using a structured questionnaire. Descriptive statistics, Fisher's exact tests, binary logistic regressions, and Mantel-Haenszel tests were used for analysis. Life-time experience with snakebites included $13.1 \%$ of respondents who reported being personally bitten and $37.4 \%$ who reported knowing of a community member being bitten. Respondents reported death after a snakebite in $9.1 \%$ of bitten community members and in $14.6 \%$ of bitten family members. Risk of snakebite was not significantly associated with sex, educational level, or occupation. Snakebite victims were most often walking (38\%) or farming (24\%) when bitten. Of those bitten, $58 \%$ went to a health facility, $30 \%$ sought traditional treatment, and $12 \%$ first went to a traditional healer before visiting a facility. Significant differences existed in perceptions on the financial consequences of snakebites among those who had been personally bitten and those who had observed a snakebite. Most commonly mentioned preventive measures were wearing shoes and carrying a light in the dark. Community engagement, including engagement with traditional healers, is needed to reduce snakebites. This should be done through education and sensitization to improve used preventive measures and effective health-seeking behavior.
\end{abstract}

\section{INTRODUCTION}

Snakebite is a major public health problem, especially affecting those living in developing countries. The WHO estimates that each year about 5 million snakebites occur, of which 2.7 million are envenomings. ${ }^{1}$ In sub-Saharan Africa, up to 32,000 snakebite deaths are estimated to occur every year, but the actual number of deaths remains unknown. ${ }^{2}$ To draw attention to the devastating impact and to coordinate a response, snakebite was pronounced a Category A Neglected Tropical Disease by the WHO in 2017. A year later Member States passed a resolution at the World Health Assembly, and in 2019 the WHO launched a global snakebite strategy for prevention and control with the aim of reducing the morbidity and mortality due to snakebite envenoming by $50 \%$ by 2030. 3 .

Despite these efforts, the health burden of snakebite, even though preventable, is enormous, and it mainly affects the poor. People living in rural regions, who often engage in some type of outdoor livelihood, are most prone to being bitten; estimates show that more than $95 \%$ of envenomings and snakebite deaths in sub-Saharan Africa occur in rural areas, especially in young, outdoor-working people and children (playing outside). ${ }^{2,5,6}$

Simple and effective treatment of snakebite envenoming has been around for decades. Good-quality antivenoms, if adequately and timely administered, can effectively reverse and cure envenoming, whereas consequences of snakebite, when not adequately and timely treated, can be death, disability, and psychological distress and stigmatization. ${ }^{2}$ Unfortunately, in sub-Saharan Africa access to health services in general, and to antivenom specifically, is generally scarce in the remote areas highly affected by snakebite, contributing to

* Address correspondence to Gaby I. Ooms, Overtoom 60-2, 1054 HK, Amsterdam, The Netherlands. E-mail: gaby@haiweb.org the high death and disability rates among snakebite victims. ${ }^{7-11}$ If treatment is obtained, its costs can be catastrophic for households when this is not covered by health insurance or available for free in the public sector. In sub-Saharan Africa, the wholesale price of one vial of antivenom ranges from US $\$ 18$ to US $\$ 200$, and the average cost of a fully effective antivenom treatment regimen is US $\$ 124 .{ }^{9}$ Also, the sometimes permanent loss of income due to disability or death can result in additional financial hardship. ${ }^{2,6}$

To improve the situation for people bitten by snakes, research is needed to fill the gaps in knowledge that exist in many sub-Saharan African countries. Evidence is needed on communities' beliefs on snakes and snakebites, on patient profiles and risk factors, and on health-seeking behavior and health outcomes after a snakebite. To further explore the lived realities of people after a snakebite, more also needs to be known about its socio-economic consequences. Together, such evidence provides a clear picture of the snakebite burden, which is needed to create buy-in at the national level for the development of context-specific health policies and tailored community-informed educational campaigns to meet local needs. To contribute to this evidence base, a household survey was conducted in four counties in Kenya with a high snakebite prevalence to determine the health, social, and economic burden of snakebites in rural communities.

\section{MATERIALS AND METHODS}

This study was designed as a quantitative cross-sectional study, consisting of a household survey.

Study area and sampling. The study was conducted in four snakebite prevalent Kenyan counties: Kajiado County, Kilifi County, Kwale County, and Taita Taveta County. ${ }^{12}$ Kenya is divided into 47 counties, and each county is further divided into subcounties. Kilifi, Kwale, and Taita Taveta counties are in the coastal region, and Kajiado County is located in the 
mainland, within the Nairobi Metropolis. The four counties share some of their borders. Venomous snakes commonly found in all four counties include the black mamba, eastern green mamba, red spitting cobra, James Ashe spitting cobra, puff adder, and boomslang. The Egyptian cobra (Kajiado County), Eastern forest cobra and yellow-bellied sea snake (Kwale and Kilifi counties), black-necked spitting cobra (Taita Taveta, Kwale, and Kajiado counties), and twig snake (Kilifi, Kwale, and Taita Taveta counties) are also venomous snakes found here. ${ }^{13}$

In each county, the median subcounty in terms of population density was selected as the study area. ${ }^{14}$ These were Kajiado Central, Kaloleni, Samburu, and Mwatata, respectively. The four subcounties have a total population of 634,366 inhabitants. ${ }^{14}$ To calculate the sample size, the following formula was used:

$$
n=\frac{Z^{2} P(1-P)}{d^{2}}
$$

where $n=$ sample size, $Z=$ level of confidence, $P=$ expected prevalence or proportion, and $d=$ margin of error. With a $95 \%$ confidence interval, the $Z$ value is $1.96, P$ is 0.5 when the expected proportion is unknown, and $d$ is set at $0.05 .{ }^{15}$ The subsequent sample size was 384 .

A probability sampling technique was used to gather 100 respondents per subcounty. The specific communities to be surveyed were randomly selected by the data collectors. They were free to choose the communities based on convenience sampling as long as the communities met the following selection criteria: 1) the community consists of at least 40 households and 2) communities surveyed within the subcounty cannot be neighboring one another. Within a community, households were selected using systematic sampling, a fixed interval selection method that is easy to use, is low cost, and has relative validity. ${ }^{16}$ The first household selected was the dwelling closest to the data collectors when arriving in the community. If this household did not want to participate or if no one was home, the neighboring dwelling was approached, until a first participant was found. Thereafter, data collectors skipped two dwellings each time after finishing a survey. Community members included in the study had to meet the following criteria: 1) living in the selected community, 2) aged 18 years or older, and 3) ability to give consent.

Data collection. Data were collected using a structured questionnaire with a mix of open-ended and closed-ended questions. Specifically, questions gathered information on household composition; income and expenditure; occupation; personal or second-hand experience with snakebites; social, financial, and health outcomes; snakebite cases in the community; beliefs about snakes and snakebites; preventive measures; and actual and hypothetical health-seeking behavior after a snakebite. The data collection tool was piloted among 10 community members in November 2019, after which slight alterations were made to improve understandability of the questions.

Due to the COVID-19 pandemic, data collection occurred in two time periods: February-March 2020 and August 2020. Data were collected using a mobile data collection application. Data collection was performed by local data collectors working in pairs and supervised by one of the authors (DO). Data collectors received a 2-day training, which included a field test of the questionnaire. The survey was conducted in English or Kiswahili, with data collectors translating the questions from English to Kiswahili and back while conducting the survey. Questions pertaining to personal experiences with snakebite were only asked if the participant indicated to have been bitten by a snake. Questions about snakebite patient profiles, actual health-seeking behavior, and health outcomes after a snakebite in the community were asked only if the participant had personal experience with a snakebite or knew a family member or community member who had been bitten by a snake. If the respondents knew a family member or community member who had been bitten, they were asked about the most commonly observed patient profiles, health-seeking behavior, and health outcomes after a snakebite. All participants were asked about their beliefs on snakebites, preventive measures, and their presumed health-seeking behavior if they were to be bitten by a snakebite.

Data management and analysis. Data were regularly uploaded to the server and downloaded into a Microsoft Excel spreadsheet by the researcher and imported into Stata. Data entries were checked for accuracy and cleaned when necessary. Missing data were excluded from the analysis. Analysis was carried out using Stata version 16. Descriptive analyses were performed to obtain frequencies and medians. Binary logistic regression and Mantel-Haenszel tests were performed to study the association between sociodemographic characteristics (sex, area, county of residence, level of education, occupation) and having experienced a snakebite. Two models were developed: 1) a model not correcting for potential confounders except for the age of the respondent and 2) a multivariate model in which all variables, including age of the respondent, were entered simultaneously. Associations are represented as odds ratios with $95 \%$ confidence intervals, and a significance level of 0.05 was used to determine statistical significance. Fisher's exact tests were performed to investigate the association between personal versus observed (among a family member or community member) snakebites and perceived social outcomes, and to test the association between personal, observed, or no experience with snakebites and beliefs on snakes, preventive measures, and health-seeking behavior. The significance level was again determined at 0.05 .

Ethical considerations. Ethical approval was granted by the Amref Health Africa Ethics and Scientific Review Committee (reference number P583-2019), and permission for the study was granted by the National Commission for Science, Technology an Innovation (license number NACOSTI/P/20/ 5492). Permission letters for the data collection were obtained from the counties' Directors of Health. Before starting the survey, participants were provided with information on the aim of the study and asked to sign an informed consent form.

COVID-19. Data collection in three counties took place from the end of February 2020 until the beginning of March 2020. As a consequence of the COVID-19 pandemic, data in Kwale County were collected in August 2020, only after the lockdown measures were lifted in Kenya and such research was allowed again. All necessary precautions to ensure the health of the respondents and data collectors were taken during this data collection period. These precautions included keeping to social distancing measures, providing all data collectors with face masks and hand sanitizer for themselves as well as for the respondents, and conducting the surveys only 
through one-on-one interviews to prevent crowding or unnecessary interaction. Further, Kwale County had a low incidence of COVID-19 cases at the time the data were collected, and data collectors adhered to the curfew measures in place during this time period.

\section{RESULTS}

In each county, respondents were surveyed from 9 to 11 different communities. Eight respondents refused to participate, and 12 were not at home at the time of the survey. Respondents were from Kajiado $(N=100)$, Kilifi $(N=93)$, Kwale $(N=$ 89), and Taita Taveta $(N=100)$ counties (Table 1). About half $(50.8 \%)$ of respondents were male, almost half of the sample had a lower (pre-primary or primary) level of education $(45.8 \%)$, and $46.6 \%$ worked in the agricultural sector. The median age was 39.5 (range: 18.0-88.0) years, and respondents had a median monthly household income of US $\$ 78.4$ (range: 4.9-2,939.2) (Supplemental Table 1).

Snakebites, health outcomes, and patient profiles. Of the 382 respondents, 50 (13.1\%) had ever been personally bitten by a snake, 55 (14.4\%) had a family member who had ever been bitten, and 143 (37.4\%) knew a community member who had been bitten (Supplemental Table 2). Respondents indicated that in the previous 12 months, a median of 1 (range: 0-6) people had been bitten in their community. Reported permanent disability as a result of the snakebite ranged from $3.6 \%$ to $9.1 \%$. A range of disabilities were mentioned, including amputations, swelling, tissue damage, nonhealing ulcers, and twisted limbs. Of the respondents who knew a family member or community member who had been bitten by a snake, 8 (14.6\%) and $15(10.5 \%)$ respondents, respectively, indicated the person bitten had died.

Snakebite was not significantly associated with sex, county, level of education, or occupation (Table 2). Although it was not statistically significant, no formal education seemed to contribute to a higher snakebite incidence, as did having an outdoor occupation compared with an indoor-based occupation. The median age of people when bitten by a snake was 34.0 (range: 8.0-67.0) years. The most common activities at the time of the bite were walking (38\%) and farming (24\%), and the majority of respondents were bitten during daylight $(60 \%)$ (Table 3$)$. No clear difference was found in dry versus rainy season in occurrences of snakebites. The feet $(48 \%)$ and legs (36\%) were the most common bite sites. In onethird of the cases, the respondent indicated that the snake was identified. Indicated snake types can be found in Table 3. In $20 \%$ of the cases, the snake was killed. The patient profiles and characteristics of the bite of those personally bitten by a snake were similar to those as most commonly described by the respondents who had observed a snakebite (Supplemental Table 3).

Health-seeking behavior after a snakebite. Almost $60 \%$ of those personally bitten by a snake went to a health facility after their bite, and $12 \%$ first went to a traditional healer before they went to a health facility (Table 3). Thirty percent only sought traditional treatment. The most common traditional treatments received were the use of a black stone or healing plants (57\%), sucking the venom from the bite (43\%), and cutting the bite $(24 \%)$. Of those who had visited a traditional healer, $29 \%$ went to a health facility afterward because they were not healed. Respondents indicated that the most common reason for consulting a traditional healer after their snakebite was because the traditional healer was close by and the health facility far away (90\%). Another reason was that it was cheaper than going to the health facility (35\%). When the respondents visited a health facility after the bite, in more than $80 \%$ of the cases they went to a public facility. In $42 \%$ of the cases, the respondents indicated they had received antivenom at the health facility. A visit to a health facility after a snakebite was more quickly initiated than a visit to a traditional healer (31.0 [range: 5.0-270.0] minutes versus 60.0

TABLE 1

Characteristics of the sample, total and stratified by county

\begin{tabular}{|c|c|c|c|c|c|c|c|c|c|c|}
\hline \multirow[b]{2}{*}{ Characteristics } & \multicolumn{2}{|c|}{ Total $(N=382)$} & \multicolumn{2}{|c|}{ Kajiado $(N=100)$} & \multicolumn{2}{|c|}{ Kilifi $(N=93)$} & \multicolumn{2}{|c|}{ Kwale $(N=89)$} & \multicolumn{2}{|c|}{ Taita Taveta $(N=100)$} \\
\hline & N & $\%$ & N & $\%$ & N & $\%$ & N & $\%$ & $N$ & $\%$ \\
\hline \multicolumn{11}{|l|}{ Sex } \\
\hline Male & 194 & 50.8 & 44 & 44.0 & 44 & 47.3 & 65 & 73.0 & 41 & 41.0 \\
\hline Female & 188 & 49.2 & 56 & 56.0 & 49 & 52.7 & 24 & 27.0 & 59 & 59.0 \\
\hline \multicolumn{11}{|l|}{ Age (years) } \\
\hline $18-25$ & 46 & 12.0 & 24 & 24.0 & 7 & 7.5 & 5 & 5.6 & 10 & 10.0 \\
\hline $26-35$ & 105 & 27.5 & 39 & 39.0 & 25 & 26.9 & 21 & 23.6 & 20 & 20.0 \\
\hline $36-45$ & 91 & 23.8 & 16 & 16.0 & 27 & 29.0 & 28 & 31.5 & 20 & 20.0 \\
\hline $46-55$ & 69 & 18.1 & 12 & 12.0 & 17 & 18.3 & 16 & 18.0 & 24 & 24.0 \\
\hline $56-65$ & 46 & 12.0 & 4 & 4.0 & 15 & 16.1 & 14 & 15.7 & 13 & 13.0 \\
\hline$\geq 66$ & 25 & 6.5 & 5 & 5.0 & 2 & 2.15 & 5 & 5.6 & 13 & 13.0 \\
\hline \multicolumn{11}{|l|}{ Head of household } \\
\hline No & 159 & 41.6 & 51 & 51.0 & 41 & 44.1 & 19 & 21.4 & 48 & 48.0 \\
\hline Yes & 223 & 58.4 & 49 & 49.0 & 52 & 55.9 & 70 & 78.7 & 52 & 52.0 \\
\hline \multicolumn{11}{|l|}{ Level of education* } \\
\hline No formal schooling & 72 & 18.9 & 32 & 32.0 & 21 & 22.6 & 4 & 4.5 & 15 & 15.0 \\
\hline Lower & 175 & 45.8 & 31 & 31.0 & 47 & 50.5 & 25 & 18.1 & 72 & 72.0 \\
\hline Higher & 135 & 35.3 & 37 & 37.0 & 25 & 26.9 & 60 & 67.4 & 13 & 13.0 \\
\hline \multicolumn{11}{|l|}{ Occupation† } \\
\hline Agricultural & 178 & 46.6 & 31 & 31.0 & 42 & 45.2 & 24 & 27.0 & 81 & 81.0 \\
\hline Indoor-based & 108 & 28.3 & 38 & 38.0 & 31 & 33.3 & 30 & 33.7 & 9 & 9.0 \\
\hline Unemployed & 83 & 21.7 & 30 & 30.0 & 17 & 18.3 & 28 & 31.5 & 8 & 8.0 \\
\hline Retired & 13 & 3.4 & 1 & 1.0 & 3 & 3.2 & 7 & 7.9 & 2 & 2.0 \\
\hline
\end{tabular}

* Low: pre-primary, primary; Higher: post-secondary, university.

† Agricultural: herding, farming; Indoor-based: shop/service worker, teacher, civil servant, health worker, student, small business owner. 
TABLE 2

Associations between snakebite and sociodemographic characteristics (total population: $N=382$ )

\begin{tabular}{|c|c|c|c|c|c|}
\hline Characteristics & $N$ (total) & $N$ (bitten) & $\%$ Bitten & Model 1, ${ }^{*}$ OR $(95 \% \mathrm{Cl})$ & Model 2,† OR $(95 \% \mathrm{Cl})$ \\
\hline \multicolumn{6}{|l|}{ Sex } \\
\hline Male & 194 & 30 & 15.5 & Ref & Ref \\
\hline Female & 188 & 20 & 10.6 & $0.72(0.38-1.34)$ & $0.61(0.30-1.24)$ \\
\hline \multicolumn{6}{|l|}{ County } \\
\hline Kajiado & 100 & 7 & 7.0 & Ref & Ref \\
\hline Kilifi & 93 & 13 & 14.0 & $1.51(0.55-4.16)$ & $1.59(0.56-4.46)$ \\
\hline Kwale & 89 & 16 & 16.9 & $1.82(0.67-4.93)$ & $2.10(0.71-6.27)$ \\
\hline Taita Taveta & 100 & 15 & 15.0 & $1.63(0.61-4.37)$ & $1.73(0.59-5.13)$ \\
\hline \multicolumn{6}{|l|}{ Level of education $\ddagger$} \\
\hline No formal schooling & 72 & 11 & 15.3 & Ref & Ref \\
\hline Lower & 175 & 27 & 15.4 & $1.14(0.51-2.54)$ & $0.84(0.35-2.04)$ \\
\hline Higher & 135 & 12 & 8.9 & $0.67(0.27-1.68)$ & $0.43(0.14-1.37)$ \\
\hline \multicolumn{6}{|l|}{ Occupation§ } \\
\hline Agricultural & 178 & 27 & 15.3 & Ref & Ref \\
\hline Indoor-based & 108 & 9 & 7.4 & $0.57(0.24-1.34)$ & $0.75(0.27-2.04)$ \\
\hline Unemployed & 83 & 10 & 12.1 & $1.08(0.47-2.49)$ & $1.32(0.53-3.33)$ \\
\hline Retired & 13 & 5 & 38.5 & $2.13(0.59-7.71)$ & $2.31(0.56-9.50)$ \\
\hline
\end{tabular}

$\mathrm{Cl}=$ confidence interval; $\mathrm{OR}=$ odds ratio; Ref $=$ reference.

*Variables were entered separately into the model. The model was corrected for age of the respondent.

† All variables were entered simultaneously into the model. The model was also corrected for age of the respondent.

‡Low: pre-primary, primary; High: vocational secondary, secondary, post-secondary, university.

§ Agricultural: herding, farming; Indoor-based: shop/service worker, teacher, civil servant, health worker, student, small business owner.

[range: 0.0-3,600.0] minutes, respectively) (Supplemental Table 4).

Financial and social consequences of the snakebite. Snakebites had an impact on people's work life: $44 \%$ indicated their ability to work was affected, $60 \%$ reported they were not able to do the same job after the snakebite as before, and $14 \%$ stated they had lost their job as a consequence of the snakebite (Table 4). Their financial situation was also affected, with $38 \%$ noting a loss of income and $20 \%$ declaring they went into debt due to the snakebite. There was a significant difference in perceptions of those who had been personally bitten by a snake and those who had observed a snakebite regarding whether the snakebite caused a loss of job $(P=0.001)$, loss of income $(P<0.001)$, or debt $(P=0.002)$. Almost half of the respondents $(46 \%)$ also indicated they were unable to afford the hospital bills for the snakebite treatment; the median out-of-pocket cost of snakebite treatment was US\$24.5 (range: 0.0-734.8) (Supplemental Table 3). Again, perceptions on this differed among those personally bitten and those who had observed a snakebite $(P<0.001)$. Social exclusion or stigmatization was reported by $6 \%$ of those personally bitten and by $3.6 \%$ of those who had observed a snakebite.

Beliefs on snakes and snakebite prevention and potential health-seeking behavior. All respondents were asked about their beliefs on snakes, preventive measures, and health-seeking behavior if they were to be bitten by a snake (hypothetical scenario). The majority of respondents (68.4\%) thought snakes bite when you step on them or disturb them (Table 5). When stratifying by personal experience with a snakebite, observing a snakebite among a family member or community member, and no experience with a snakebite, responses differed significantly between the groups for the answer option "snakes bite when they are scared" $(P=$ 0.004 ), which was more often selected by those who had personally experienced a snakebite, and "don't know" ( $P=$ $0.015)$, which was more often selected by those with no experience with snakebites.

There was a range of preventive measures mentioned by the respondents, including wearing shoes (49.5\%), carrying a light in the dark $(44.7 \%)$, and ensuring no snakes can enter the house by covering holes and openings (25.7\%). Not hurting or touching a snake was mentioned by $23.3 \%$ of the respondents, whereas its opposite measure, killing a snake, was mentioned by $20.6 \%$ of the respondents. No significant differences in responses were found when stratified based on experience with snakebites.

When respondents were asked about their hypothetical health-seeking behavior after a snakebite, the majority would use (traditional) first aid methods (52.6\%) and would go to a health facility $(84.5 \%)$. Only $6.1 \%$ indicated they would go to a traditional healer. When stratified by experience with snakebite, there was a significant difference in the choice of going to a health facility after a snakebite or not with those having experienced a snakebite choosing the option of going to a health facility less often than the other two groups $(P=0.001)$. When asked about the traditional first aid they would use, using a tight bandage or tourniquets $(78.5 \%)$, using a black stone $(46.5 \%)$, and cutting the bite $(24.5 \%)$ were the most commonly mentioned practices. The potential use of a black stone if the respondent were to be bitten by a snake differed significantly between the stratified groups $(P=0.044)$. The fact that the health facility is far away $(52.8 \%)$ and care at the health facility being expensive (34.0\%) were the reasons given why respondents would not visit a health facility if they were to be bitten by a snake. The medicines that were most commonly indicated by respondents that should be used after a snakebite were antivenom (58.9\%), antibiotics (39.1\%), and pain killers (32.3\%).

\section{DISCUSSION}

This study aimed to provide a broad overview of the extent of the problem and impact of snakebite in four snakebiteprevalent counties in Kenya. Although it does not intend to provide a generalizable incidence or prevalence of snakebites in the counties, it does indicate the extent to which these communities are affected by snakebite and can be used as a baseline to guide the development of policies and programs shaped to local needs. It is especially important in the current context where shifting priorities due to the COVID-19 
TABLE 3

Characteristics of the snakebite and health-seeking behavior

\begin{tabular}{|c|c|c|c|c|c|}
\hline \multirow[b]{2}{*}{ Characteristics } & \multicolumn{5}{|c|}{ Personally bitten $(N=50)$} \\
\hline & N & $\%$ & & N & $\%$ \\
\hline Age when bitten (years) & & & Care sought & & \\
\hline $0-17$ & 7 & 14 & Traditional treatment & 15 & 30 \\
\hline $18-25$ & 9 & 18 & Healthcare at facility & 29 & 58 \\
\hline $26-35$ & 13 & 27 & Traditional treatment and healthcare & 6 & 12 \\
\hline $36-45$ & 12 & 25 & Traditional treatment received & & \\
\hline$\geq 46$ & 8 & 16 & Black stone & 12 & 57 \\
\hline Activity at time of bite & & & Healing plants & 12 & 57 \\
\hline Walking & 19 & 38 & Suck out venom & 9 & 43 \\
\hline Farming & 12 & 24 & Cut bite & 5 & 24 \\
\hline Collecting firewood & 5 & 10 & Tourniquet & 2 & 10 \\
\hline Herding & 4 & 8 & Wash bite & 2 & 10 \\
\hline Sleeping & 3 & 6 & Burn bite & 1 & 5 \\
\hline Charcoal burning & 2 & 4 & Outcome traditional treatment & & \\
\hline Activity inside house & 2 & 4 & Fully healed & 15 & 71 \\
\hline Playing & 1 & 2 & Not fully healed, went to facility & 6 & 29 \\
\hline Don't know & 2 & 4 & Reason for visiting traditional healer & & \\
\hline Part of the day when bitten & & & Close by, facility too far away & 18 & 90 \\
\hline During daylight & 30 & 60 & Cheap, facility too expensive & 7 & 35 \\
\hline In the dark & 20 & 40 & Only one who can treat snakebite & 3 & 15 \\
\hline Season when bitten* & & & No treatment available at facility & 3 & 15 \\
\hline Dry season & 18 & 36 & Provides first aid & 1 & 5 \\
\hline Rainy season & 15 & 30 & Sector facility visited & & \\
\hline Don’t know & 17 & 34 & Public & 28 & 85 \\
\hline Body part bitten & & & Private & 2 & 6 \\
\hline Foot & 24 & 48 & Private not-for-profit & 3 & 9 \\
\hline Leg & 18 & 36 & Treatment received at facility & & \\
\hline Arm & 6 & 12 & Antivenom & 14 & 42 \\
\hline Hand & 2 & 4 & Antibiotics & 12 & 36 \\
\hline Snake identified & & & Painkillers & 9 & 27 \\
\hline No & 17 & 34 & Anti-tetanus injection & 8 & 24 \\
\hline Yes & 17 & 34 & Referred to another facility & 6 & 18 \\
\hline Don’t know & 16 & 32 & Fluids & 3 & 9 \\
\hline Type of snake† & & & Adrenaline & 2 & 6 \\
\hline Black mamba & 10 & 59 & Antihistamine & 1 & 3 \\
\hline Red spitting cobra & 5 & 29 & Surgery & 1 & 3 \\
\hline Egyptian cobra & 1 & 6 & Don't know & 4 & 12 \\
\hline Vine snake & 1 & 6 & & & \\
\hline \multicolumn{6}{|l|}{ What happened to snake } \\
\hline It slithered away & 36 & 72 & & & \\
\hline It was killed & 10 & 20 & & & \\
\hline It stayed in the same place & 3 & 6 & & & \\
\hline It was not seen & 1 & 2 & & & \\
\hline
\end{tabular}

$\dagger$ Type of snake as identified by the victim. Correct identification of the type of snake is therefore not certain.

pandemic are likely to affect snakebite prevention and care on all levels negatively. Therefore, within a rapidly changing environment, evidence on the effects of snakebite, both past and present, within rural communities can provide the authorities with valuable insights to shape policies informed by realities on the ground. This is even more necessary in the absence of any mechanisms to collect robust data on snakebites in communities in Kenya.

Our results show that snakebites were common in the surveyed communities; more than one-third of the surveyed community members had some experience with snakebites, and it frequently led to death or disability. This study also provides evidence of the demographic characteristics of those affected: the median age of those bitten was 34.0 years, with the majority aged $26-45$ years. Further, traditional healing still played an important role in the treatment of snakebites in the surveyed communities. Some of the known preventive measures included wearing shoes and carrying a light in the dark, although these measures were not known by all. The most common first aid methods that would be used after a bite, which were all ineffective practices, included the use of tourniquets, black stones, and cutting the bite. Last, snakebites affect victims both socially and financially. Box 1 provides a summary of recommendations following from this research, which are explained in more detail below.

The age profile found in our study is similar to what has been found in other sub-Saharan African countries. ${ }^{17-21}$ Our sample showed no significant differences in snakebites between sex, occupation, or level of education. Previous studies undertaken in sub-Saharan Africa found the same, ${ }^{17,22,23}$ with the exception of one study that showed that farmers were more likely to be bitten than those with any other occupation. ${ }^{20}$ The relatively small sample size in our study might explain why we did not find any associations, although our results seemed to imply that no formal education and having an outdoor occupation contributed to a higher snakebite incidence. Other studies not testing for significance showed patterns of higher snakebite incidence among farmers and those with a 
TABLE 4

Financial and social consequences of a snakebite, personally experienced and observed

\begin{tabular}{|c|c|c|c|c|c|}
\hline & \multicolumn{2}{|c|}{ Personally bitten $(N=50)$} & \multicolumn{2}{|c|}{ Observed snakebite $(N=141)$} & \multirow[b]{2}{*}{$P$ value } \\
\hline & N & $\%$ & $N$ & $\%$ & \\
\hline \multicolumn{6}{|c|}{ Ability to work affected by snakebite } \\
\hline No & 27 & 54.0 & NA & NA & \multirow[t]{3}{*}{-} \\
\hline Yes & 22 & 44.0 & NA & NA & \\
\hline Don’t know & 1 & 2.0 & NA & NA & \\
\hline \multicolumn{6}{|c|}{ Able to do same job after snakebite as before } \\
\hline No & 30 & 60.0 & NA & NA & \multirow[t]{3}{*}{-} \\
\hline Yes & 17 & 34.0 & NA & NA & \\
\hline Don't know & 3 & 6.0 & NA & NA & \\
\hline \multicolumn{6}{|c|}{ Loss of job due to snakebite } \\
\hline No & 42 & 84.0 & 99 & 70.2 & \multirow[t]{3}{*}{0.001} \\
\hline Yes & 7 & 14.0 & 10 & 7.1 & \\
\hline Don't know & 1 & 2.0 & 32 & 22.7 & \\
\hline \multicolumn{6}{|c|}{ Loss of income due to snakebite } \\
\hline No & 29 & 58.0 & 100 & 70.9 & \multirow{3}{*}{$<0.001$} \\
\hline Yes & 19 & 38.0 & 17 & 12.1 & \\
\hline Don't know & 2 & 4.0 & 24 & 17.0 & \\
\hline \multicolumn{6}{|c|}{ Debt due to snakebite } \\
\hline No & 38 & 76.0 & 93 & 66.0 & \multirow[t]{3}{*}{0.002} \\
\hline Yes & 10 & 20.0 & 14 & 9.9 & \\
\hline Don't know & 2 & 4.0 & 34 & 24.1 & \\
\hline \multicolumn{6}{|c|}{ Unable to afford hospital bills for snakebite treatment } \\
\hline No & 26 & 52.0 & 93 & 66.4 & \multirow[t]{3}{*}{$<0.001$} \\
\hline Yes & 23 & 46.0 & 16 & 11.4 & \\
\hline Don't know & 1 & 2.0 & 31 & 22.1 & \\
\hline \multicolumn{6}{|c|}{ Socially excluded or stigmatized because of snakebite } \\
\hline No & 45 & 90.0 & 114 & 80.9 & \multirow[t]{3}{*}{0.063} \\
\hline Yes & 3 & 6.0 & 5 & 3.6 & \\
\hline Don't know & 2 & 4.0 & 22 & 15.6 & \\
\hline
\end{tabular}

$\mathrm{NA}=$ not applicable.

lower educational status similar to our findings. ${ }^{12,21,24,25}$ Further, although occupation was not shown to be associated with snakebite, this study does show snakebite victims were most often outside, performing activities such as walking, farming, or collecting firewood, when they were bitten by a snake. This is in line with studies in other countries ${ }^{24,26}$ and with one study done in Kenya. ${ }^{27}$

This study further showed that, although many of the snakebite victims visited a health facility after the bite, there was still a considerable proportion that also made use of traditional treatment, either solely or in combination with their visit to the health facility. This has also been shown to be the case in another study conducted in Western Kenya. ${ }^{27}$ Traditional treatments, such as the use of a black stone, healing plants, tourniquets, sucking the venom from the bite, or cutting the bite, have not been proven to be effective against envenomings; on the contrary, research has shown that these methods can have adverse consequences because they might cause infections or additional health problems and delay the administration of effective treatment such as antivenom. ${ }^{28}$ These traditional treatments are also adopted as first aid by many of the community members: almost $80 \%$ said they would use a tourniquet after a bite, and almost half would put a black stone on the wound, indicating that sensitization efforts should focus on teaching communities what effective first aid entails. Further, efforts to include traditional healers in the healthseeking pathways in Kenya might reduce the delay in snakebite victims receiving proper medical care after envenomings: If traditional healers are able to provide effective and appropriate first aid, after which they refer victims directly to health facilities, serious disabilities and even deaths could be prevented.
When snakebite victims went to a health facility, $42 \%$ reported to have received antivenom. This finding should, however, be interpreted cautiously. It is possible that respondents' knowledge on the specific medications administered is uncertain, especially in emergency situations such as snakebites. It is further unknown whether antivenom was not provided to all the patients in our research because not all bites were envenomings or because it was unavailable. However, previous research conducted in Kenya showed that antivenom was available at only $27 \%$ of surveyed health facilities and that unavailability and stock-outs were common. ${ }^{12,25}$ Further, the cases in this study are only those that survived their snakebite; snakebite victims who might have died because there was no antivenom treatment available could not be surveyed. Ensuring that effective antivenom is available at health facilities is thus crucial. To facilitate this, snakebite should be prioritized by the Kenyan Ministry of Health within its broader health policy frameworks and master plans while at the same time ensuring translation of all four pillars specified within the WHO's snakebite strategy. ${ }^{29}$ Further, to properly capture the prevalence of snakebites, existing health surveillance systems need to be strengthened to adequately collect, report, and evaluate snakebite cases in both communities and health facilities.

This study is one of the first in sub-Saharan Africa that specifically included questions on the socio-economic impact of snakebite and showed that financial consequences are common: Many had experienced a loss of income and high hospital bills, and ability to work or do the same job afterward was also often affected. Further, we found that, in our sample, costs incurred for snakebite treatment were as high as US\$734.80, whereas the median monthly household income 
TABLE 5

Beliefs on snakes and snakebite prevention, and hypothetical health-seeking behavior if a snakebite occurred, stratified per snakebite experience

\begin{tabular}{|c|c|c|c|c|c|c|c|c|c|}
\hline \multirow[b]{2}{*}{ Beliefs } & \multicolumn{2}{|c|}{ Total $(N=382)$} & \multicolumn{2}{|c|}{ Personal snakebite $(N=51)$} & \multicolumn{2}{|c|}{ Observed snakebite $(N=141)$} & \multicolumn{2}{|c|}{ No experience $(N=191)$} & \multirow[b]{2}{*}{$P$ value } \\
\hline & $N$ & $\%$ & N & $\%$ & $N$ & $\%$ & N & $\%$ & \\
\hline \multicolumn{10}{|l|}{ Reasons why snakes bite } \\
\hline Hungry & 11 & 2.9 & 1 & 2.0 & 4 & 2.8 & 6 & 3.2 & 1.000 \\
\hline Scared & 61 & 16.1 & 15 & 30.6 & 25 & 17.7 & 21 & 11.1 & 0.004 \\
\hline Stepped on/disturbed & 260 & 68.4 & 32 & 65.3 & 98 & 69.5 & 130 & 68.4 & 0.851 \\
\hline Animals in house & 30 & 7.9 & 5 & 10.2 & 11 & 7.8 & 14 & 7.4 & 0.774 \\
\hline Accident & 9 & 2.4 & 2 & 4.1 & 3 & 2.1 & 4 & 2.4 & 0.651 \\
\hline Sent by bad spirits & 37 & 9.7 & 2 & 4.1 & 15 & 10.6 & 20 & 10.5 & 0.388 \\
\hline Sent by somebody to harm & 39 & 10.3 & 8 & 16.3 & 15 & 10.6 & 16 & 8.4 & 0.238 \\
\hline No reason & 23 & 6.1 & 2 & 4.1 & 12 & 8.5 & 9 & 4.7 & 0.336 \\
\hline Don't know & 44 & 11.6 & 4 & 8.2 & 9 & 6.4 & 31 & 16.3 & 0.015 \\
\hline \multicolumn{10}{|l|}{ Preventive measures } \\
\hline Wear shoes & 187 & 49.5 & 25 & 51.0 & 66 & 47.1 & 96 & 50.8 & 0.797 \\
\hline Carry a light in the dark & 169 & 44.7 & 23 & 46.9 & 54 & 38.6 & 92 & 48.7 & 0.179 \\
\hline Ensure no snake can enter house & 97 & 25.7 & 11 & 22.5 & 38 & 27.1 & 48 & 25.4 & 0.821 \\
\hline Do not hurt or touch snakes & 88 & 23.3 & 14 & 28.6 & 31 & 22.1 & 43 & 22.8 & 0.636 \\
\hline Kill snake & 78 & 20.6 & 7 & 14.3 & 27 & 19.3 & 44 & 23.2 & 0.364 \\
\hline Preventive herbs around house & 55 & 14.6 & 7 & 14.3 & 21 & 15.0 & 27 & 14.3 & 0.979 \\
\hline No animals in house & 49 & 13.0 & 5 & 10.2 & 22 & 15.7 & 22 & 11.6 & 0.489 \\
\hline Preventive spray around house & 49 & 13.0 & 5 & 10.2 & 16 & 11.4 & 28 & 14.8 & 0.607 \\
\hline Clear bushes around house & 30 & 7.9 & 2 & 4.1 & 7 & 5.0 & 21 & 11.1 & 0.092 \\
\hline Don’t know & 8 & 2.1 & 2 & 4.1 & 4 & 2.9 & 2 & 1.1 & 0.221 \\
\hline \multicolumn{10}{|l|}{ Type of care after bite } \\
\hline Traditional healer & 23 & 6.1 & 6 & 12.2 & 7 & 5.0 & 10 & 5.3 & 0.185 \\
\hline First aid & 200 & 52.6 & 23 & 46.9 & 81 & 57.5 & 96 & 50.5 & 0.315 \\
\hline Community health worker & 71 & 18.7 & 9 & 18.4 & 23 & 16.3 & 39 & 20.5 & 0.620 \\
\hline Health facility & 321 & 84.5 & 33 & 67.4 & 115 & 81.6 & 173 & 91.1 & 0.001 \\
\hline \multicolumn{10}{|l|}{ First aid after bite* } \\
\hline Tourniquet & 157 & 78.5 & 17 & 73.9 & 59 & 72.8 & 81 & 84.4 & 0.141 \\
\hline Black stone & 93 & 46.5 & 12 & 52.2 & 29 & 35.8 & 52 & 54.2 & 0.044 \\
\hline Cut the bite & 49 & 24.5 & 3 & 13.0 & 23 & 28.4 & 23 & 24.0 & 0.329 \\
\hline Wash the bite & 16 & 8.0 & 0 & 0.0 & 7 & 8.6 & 9 & 9.4 & 0.397 \\
\hline Pain killers & 13 & 6.5 & 1 & 4.4 & 5 & 6.2 & 7 & 7.3 & 1.000 \\
\hline Antibiotics & 11 & 5.5 & 1 & 4.4 & 3 & 3.7 & 7 & 7.3 & 0.624 \\
\hline
\end{tabular}

*Only asked if respondent indicated they would use first aid after a snakebite.

was US\$78.40. Such findings have also been reported in Bangladesh, India, and Sri Lanka. ${ }^{30-32}$ This research is also the first to ask community members who had only observed a snakebite but who had not experienced it personally about the socio-economic consequences of snakebite. Interestingly, they gave lower estimates of the financial impact of snakebites on those bitten. This finding might not be surprising because financial difficulties are seen as a personal problem and therefore might not be shared openly with others. It is also possible that others might underestimate the impact snakebite has had on victims because the impact of diseases is generally underestimated by outsiders, especially if the disease is stigmatized or not prioritized within a health system. These findings underscore the considerable financial impact snakebite has, which is not only felt by the victims but also by their families because income and jobs are regularly lost. Combined with the patient profile outlined in this study, our findings confirm that the impact of snakebite is felt strongly by those who might already be struggling to support themselves and their dependents. Efforts should focus on reducing snakebite incidences. For those that do occur, decreasing the financial and health burden for victims by ensuring adequate treatment, including antivenom, is available at the nearest public health facilities, where treatment is offered for free to the patient, is paramount. This will directly affect the financial burden because the victim will not need to pay for their treatment out-of-pocket and indirectly because ensuring proper treatment is available will diminish the chance of long-term disability or death. In the future, in-depth studies on the socio-economic consequences of snakebites, including the impact on victims' and their families' mental health, should be undertaken to enable full understanding of the long-term impact of snakebite.

More than $80 \%$ of the snakebite victims in our sample were bitten in the foot or leg, underscoring how wearing closed shoes or boots might help prevent a large proportion of the snakebites. A study conducted in coastal Kenya showed that less than $50 \%$ of the population wears shoes. ${ }^{33}$ Community sensitization should focus on this specifically because, in line with those findings, only half of respondents indicated the wearing of shoes as a preventive measure. This study also showed that knowledge on recommended preventive measures in general has room for improvement and should be covered in sensitization efforts because none of the effective measures was mentioned by a majority of the respondents, whereas incorrect measures (e.g., killing snakes when you see them) were indicated, and other effective measures (e.g., using mosquito nets to prevent snakes from entering your bed) were not mentioned at all. ${ }^{34}$

Strengths and limitations. Although this is the first study in Kenya to quantitatively research the burden of snakebite in rural communities, some limitations to this study should be 
noted. First, recall bias of snakebite victims might have played a role in our study because we asked about lifetime experience with snakebite, and not just about, for example, snakebites in the previous year. Nevertheless, snakebites are often experienced as being traumatic, which we believe allows for better knowledge retainment of the event than for events that happen in everyday life. Second, our study might be affected by its sample size, specifically the sample of those personally bitten, which limited the strength of the association analyses. Increasing the sample size and using cluster sampling is suggested for future research to establish the effects found in this research with more certainty. Third, no questions about the patient profiles or healthseeking behavior of snakebite victims who had died were asked. As a consequence, we might have missed information about the most severe cases that occurred in the community. It is therefore also possible that the snakebite problem is even bigger than illustrated in our research. This might be researched in the future through interviews with the victims' relatives. Related, despite ongoing concerns on the availability of certain antivenom products that may lack efficacy in Kenya, we were unable to identify what antivenom products were administered to the patients in our sample and the performance of those products on the patient outcomes. This could be researched in the future, making use of patient medical records that comprehensively document snakebite cases, including treatment efficacy and patient outcomes. Fifth, respondents were asked about their occupation at the time of the survey but were not asked about their occupation at the time of the bite. This might have led to a distortion in the relationship between occupation and snakebite. Nevertheless, this study provides a useful, first indication of the extent to which Kenyan communities are affected by snakebite and highlights the gaps in knowledge on prevention strategies and proper first-aid methods. This study can be used as a baseline to guide the development of context-specific programs, targeting these knowledge gaps.

\section{CONCLUSIONS}

This study conducted in four snakebite-endemic counties in Kenya showed that snakebites are a common occurrence in rural communities, leading to death and disability. The majority of snakebite victims were 26-45 years of age and were often walking or farming when the bite occurred. Traditional healing still plays an important role in the treatment of snakebites in Kenya, and snakebites have a considerable impact on victims, both socially and financially. To reduce this burden felt by rural communities, a multipronged approach is needed, consisting of on the one hand community engagement, including engagement with traditional healers, through education and sensitization efforts to improve used preventive measures and effective health-seeking behavior. On the other hand, health system strengthening is needed so snakebite victims who present to health facilities can be quickly and adequately treated with appropriate antivenom and supportive care that is affordable to them. For this, the government needs to adopt policies and programs financed to ensure healthcare workers are adequately trained, antivenom and supportive treatments are supplied, cases are recorded, and communities are fully engaged.
Box 1

Recommendations to reduce the burden of snakebite in rural Kenyan communities

- Community sensitization on effective preventive measures and first-aid practices to reduce snakebite incidences and the use of ineffective practices.

- Include traditional healers as first-responders in healthseeking pathways as first aid providers and for referrals to health facilities.

- Ensure availability of free, effective antivenom and supportive treatment at health facilities.

- Strengthen existing health surveillance systems to adequately collect, report and evaluate snakebite cases in communities and health facilities.

- Undertake frequent qualitative research to capture the broader societal and economic impacts on snakebite-affected victims, families, and communities.

- Identify and address the holistic needs of snakebite victims with disabilities through the development of community-led and community-based projects and services.

- Ensure snakebite is prioritized by the Kenyan Ministry of Health within broader health policy frameworks and master plans while ensuring translation of all four pillars specified within the WHO's snakebite strategy.

Received March 3, 2021. Accepted for publication April 25, 2021.

Published online July 19, 2021.

Note: Supplemental tables appear at www.ajtmh.org.

Acknowledgments: We thank the data collectors for their support in this research and all the respondents for the time taken to participate in this study.

Financial support: This work was supported by the Lillian Lincoln Foundation and the Hennecke Foundation. The funders had no role in study design, data collection and analysis, decision to publish, or preparation of the manuscript.

Authors' addresses: Gaby I. Ooms, Health Action International, Amsterdam, The Netherlands, and Utrecht Centre for Pharmaceutical Policy and Regulation, Division of Pharmacoepidemiology and Clinical Pharmacology, Utrecht Institute for Pharmaceutical Sciences (UIPS), Utrecht University, Utrecht, The Netherlands, E-mail: gaby@haiweb. org. Janneke van Oirschot, Benjamin Waldmann, and Tim Reed, Health Action International, Amsterdam, The Netherlands, E-mails: janneke@haiweb.org, ben@haiweb.org, and tim@haiweb.org. Dorothy Okemo, Access to Medicines Platform Kenya, Nairobi, Kenya, E-mail: dorojuma@gmail.com. Aukje K. Mantel-Teeuwisse and Hendrika A. van den Ham, Utrecht Centre for Pharmaceutical Policy and Regulation, Division of Pharmacoepidemiology and Clinical Pharmacology, Utrecht Institute for Pharmaceutical Sciences (UIPS), Utrecht University, Utrecht, The Netherlands, E-mails: a.k.mantel@ uu.nl and h.a.vandenham@uu.nl.

\section{REFERENCES}

1. World Health Organization, 2019. Snakebite Envenoming: What Is Snakebite Envenoming? Geneva, Switzerland: WHO. Available at: https://www.who.int/snakebites/disease/en/. Accessed February 1, 2019.

2. Gutiérrez JM, Calvete JJ, Habib AG, Harrison RA, Williams DJ, Warrell DA, 2017. Snakebite envenoming. Nat Rev Dis Primers 3: $1-21$.

3. World Health Organization, 2020. Snakebite Envenoming. Geneva, Switzerland: WHO. Available at: https://www.who.int/newsroom/fact-sheets/detail/snakebite-envenoming. Accessed February 1, 2019.

4. World Health Assembly, 2018. Addressing the Burden of Snakebite Envenoming. Available at: https://apps.who.int/iris/handle/ 10665/279476. Accessed February 1, 2019. 
5. Chippaux JP, 2011. Estimate of the burden of snakebites in subSaharan Africa: a meta-analytic approach. Toxicon 57: 586599.

6. World Health Organization, 2019. Snakebite Envenoming: Prevalence of Snakebite Envenoming. Geneva, Switzerland: WHO. Available at: https://www.who.int/snakebites/epidemiology/ en/. Accessed February 1, 2019.

7. Longbottom $J$ et al., 2018. Vulnerability to snakebite envenoming: a global mapping of hotspots. Lancet 392: 673-684.

8. Simpson ID, Blaylock RSM, 2009. The anti snake venom crisis in Africa: a suggested manufacturers product guide. Wilderness Environ Med 20: 275-282.

9. Brown NI, 2012. Consequences of neglect: analysis of the subsaharan african snake antivenom market and the global context. PLoS Negl Trop Dis 6: 1-7.

10. Habib AG, Brown NI, 2018. The snakebite problem and antivenom crisis from a health-economic perspective. Toxicon 150: 115123.

11. Theakston RDG, Warrell DA, 2000. Crisis in snake antivenom supply for Africa. Lancet 356: 2104.

12. Ooms Gl, van Oirschot J, Waldmann B, von Bernus S, van den Ham HA, Mantel-Teeuwisse AK, Reed T, 2021. The current state of snakebite care in Kenya, Uganda, and Zambia: healthcare workers' perspectives and knowledge, and health facilities' treatment capacity. Am J Trop Med Hyg 104: 774-782.

13. Ministry of Health Government of Kenya, 2019. Guidelines for Prevention Diagnosis and Management of Snakebite Envenoming in Kenya. Nairobi, Kenya: Ministry of Health.

14. Kenya National Bureau of Statistics, 2019. 2019 Kenya Population and Housing Census. Volume 1: Population by County and SubCounty. Vol I. Nairobi, Kenya: Kenya National Bureau of Statistics.

15. Naing L, Winn T, Rusli BN, 2006. Practical issues in calculating the sample size for prevalence studies. Arch Orofac Sci 1: 9-14.

16. Taherdoost $H, 2016$. Sampling methods in research methodology: how to choose a sampling technique for research. Int $J$ Acad Res Manag 5: 1-11.

17. Musah Y, Ameade EPK, Attuquayefio DK, Holbech LH, 2019. Epidemiology, ecology and human perceptions of snakebites in a savanna community of northern Ghana. PLoS Negl Trop Dis 13: 1-20.

18. Birhanu Hurisa AMA, 2014. Epidemiological survey of snake bite in Ethiopia. Epidemiol Open Access 04.

19. Kipanyula MJ, Kimaro WH, 2015. Snakes and snakebite envenoming in northern Tanzania: a neglected tropical health problem. J Venom Anim Toxins Incl Trop Dis 21: 1-8.

20. Tchoffo D, Kamgno J, Kekeunou S, Yadufashije C, Nana Djeunga HC, Nkwescheu AS, 2019. High snakebite underreporting rate in the centre region of Cameroon: an observational study. BMC Public Health 19: 1040.

21. Alcoba G, Chabloz M, Eyong J, Wanda F, Ochoa C, Comte E, Nkwescheu A, Chappuis F, 2020. Snakebite epidemiology and health-seeking behavior in Akonolinga health district, Cameroon: cross-sectional study. PLoS Negl Trop Dis 14: 1-15.

22. Nasio NA, 2016. Snake bites: a forgotten menace in Kenya. Int $J$ Sci Res Innov Technol 3: 1-7.

23. Wood D, Sartorius B, Hift R, 2016. Snakebite in north-eastern South Africa: clinical characteristics and risks for severity. $S$ Afr Fam Pract 58: 62-67.

24. Punguyire D, Baiden F, Nyuzaghl J, Hultgren A, Berko $Y$, Brenner S, Soghoian S, Adjei G, Niyogi A, Moresky R, 2014. Presentation, management, and outcome of snake-bite in two district hospitals in Ghana. Pan Afr Med J 19: 1-9.

25. Ochola FO, Okumu MO, Muchemi GM, Mbaria JM, Gikunju JK, 2018. Epidemiology of snake bites in selected areas of Kenya. Pan Afr Med J 29: 217.

26. Tochie JN, Temgoua MN, Njim T, Celestin D, Tankeu R, Nkemngu NJ, 2017. The neglected burden of snakebites in Cameroon: a review of the epidemiology, management and public health challenges. BMC Res Notes 10: 405.

27. Okumu MO, Patel MN, Bhogayata FR, Ochola FO, Olweny IA, Onono JO, Gikunju JK, 2019. Management and cost of snakebite injuries at a teaching and referral hospital in western Kenya. F1000 Res 8: 1588.

28. Avau B, Borra V, Vandekerckhove P, De Buck E, 2016. The treatment of snake bites in a first aid setting: a systematic review. PLoS Negl Trop Dis 10: 1-20.

29. World Health Organization, 2019. Snakebite Envenoming. A Strategy for Prevention and Control. Geneva, Switzerland: WHO

30. Hasan SMK, Basher A, Molla AA, Sultana NK, Faiz MA, 2012. The impact of snake bite on household economy in Bangladesh. Trop Doct 42: 41-43.

31. Vaiyapuri $S$ et al., 2013. Snakebite and its socio-economic impact on the rural population of Tamil Nadu, India. PLoS One 8: e80090.

32. Kasturiratne A, Pathmeswaran A, Wickremasinghe AR, Jayamanne SF, Dawson A, Isbister GK, de Silva HJ, Lalloo DG, 2017. The socio-economic burden of snakebite in Sri Lanka. PLoS Negl Trop Dis 11: 1-9.

33. Halliday KE et al., 2019. Community-level epidemiology of soiltransmitted helminths in the context of school-based deworming: baseline results of a cluster randomised trial on the coast of Kenya. PLoS Negl Trop Dis 13: 1-22.

34. Health Action International. Snakebite First Aid, 2020. Available at: https://haiweb.org/wp-content/uploads/2019/07/HAl-snakebitePoster-A1-841x594mm-UGANDA-min.pdf. 